\title{
THE EFFECT OF REMEDIAL INSTRUCTION USING ADAPTIVE-LEARNING PLATFORM ON MATHEMATICAL ACHIEVEMENTS OF SEVENTH GRADERS
}

\author{
Shu-Chuan Shih, Jiun-Shian Li, \& Bor-Chen Kuo \\ Graduate Institute of Educational Information and Measurement, \\ National Taichung University of Education (Taiwan)
}

\begin{abstract}
This study aimed to examine the effect of remedial instruction using adaptive-learning platform on mathematical achievements in the mixed operations with integers unit of seventh grade math. The system used in this study was developed for grade 1 to 9 math learning in Taiwan based on the knowledge structure theory. A quasi-experimental design was adopted to evaluate the effectiveness of the system. The participants were 141 seventh graders from three junior high schools in Taichung city. The experimental and control group included 76 and 65 students respectively. The adaptive-learning platform was used for the experimental group to receive the computerized adaptive remedial instruction based on individual diagnosis report, and the control group received the traditional remedial instruction with the lecture given by their teacher based on the testing report of the whole class. The result showed that the performance of experimental group was significantly better than that of control group. Moreover, most students (more than 70\%) in the experimental group demonstrated positive attitude to the adaptive-learning platform.
\end{abstract}

Keywords: Adaptive learning, mixed operations with integers, individual diagnosis report, remedial math instruction.

\section{Introduction}

Recently, adaptive learning is an important research issue for developing e-learning systems. Adaptive learning is a student-focused approach to creating a personalized learning experience for students that employs "a data-driven, and in some cases, nonlinear approach to instruction and remediation, adjusting to a learner's interactions and demonstrated performance level, and subsequently anticipating what types of content and resources learners need at a specific point in time to make progress." (Waters, 2014). Many studies have been showing that adaptive learning technology can help students achieve comparable results in less time, raise their scores, and improve retention (Wells \& McCrory, 2011; Yang, Hwang, \& Yang, 2013; Zimmer, 2014; Wu, Kuo, \& Wang, 2017). However, little research has been done on the the effect of math adaptive-learning in Taiwan. To fill this research gap, the goal of this study is to examine the effect of remedial instruction using adaptive-learning platform (Ministry of Education in Taiwan, 2016) on mathematical achievements in the mixed operations with integers unit of seventh grade math.

\section{Method}

The system used in this study was developed for grade 1 to 9 math learning in Taiwan based on the knowledge structure theory. In this study, we took the mixed operations with integers unit of seventh grade math as an example, the procedures for constructing online teaching content of the system were as follows. First, analyzing teaching objectives, defining the important concepts and their sequence of the unit by the domain experts. Second, depicting relationships among these concepts in a tree diagram which was called knowledge structure. Third, constructing diagnostic tests and adaptive remedial teaching videos according to each concept node (there were 29 nodes in this unit). A quasi-experimental design was adopted to evaluate the effectiveness of the system. The participants were 141 seventh graders from three junior high schools in Taichung city. The experimental and control group included 76 and 65 students respectively. The experiment lasted for 4 classes. The adaptive-learning platform was used for 
the experimental group to receive the computerized adaptive remedial instruction based on individual diagnosis report, and the control group received the traditional remedial instruction with the lecture given by their teacher based on the testing report of the whole class. The participants finished the pretest and post-test of "mixed operations with integers" respectively (two tests consisted of 40 items were parallel forms with the Cronbach $\alpha$ reliability coefficient of .89) to compare the differences in mathematical achievements between the two groups. A one-way analysis of covariance (ANCOVA) was conducted using pretest scores as the covariant, the remedial approaches as an independent variable, and the post-test scores as a dependent variable.

\section{Results}

\subsection{Evaluating the learning effect of two remedial instructions}

The test of homogeneity of regression coefficients was administered before ANCOVA, obtaining the results $\mathrm{F}=.370$ and $\mathrm{p}=.554>.05$; this indicated that it fulfills the basic assumption of the homogeneity of the regression coefficients in ANCOVA. Then, one-way ANCOVA was implemented. The result showed that the experimental group significantly outperformed the control group, with $\mathrm{F}=563.088\left(\mathrm{p}=.000<.05, \eta^{2}=.825\right)$, and the adjusted mean was 31.45 of the experimental group and 30.20 of the control group, respectively (the highest grade was 40). This finding supported the effectiveness of adaptive-learning platform on mathematical achievements.

\subsection{The usability and user experience survey}

To find out students' feelings about using the math adaptive-learning platform, those in the experimental group were requested to complete a questionnaire of usability and user experience with math adaptive-learning, which included 9 items with four-point scales (e.g., strongly agree, agree, disagree, strongly disagree). Most students (more than 70\%) in the experimental group demonstrated positive attitude to the adaptive-learning platform.

\section{References}

Ministry of Education in Taiwan (2016). An adaptive e-learning project in Taiwan. Taipei: Republic of China Press. Http://210.65.89.151/index_AIAL2.php?t=1555636473

Waters, J. K. (2014). Adaptive learning: Are we there yet?. THE Journal (Technological Horizons in Education), 41(4), 12.

Wells, A. T., \& McCrory, R. (2011). Hypermedia and learning: Contrasting interfaces to hypermedia systems. Computers in human behavior, 27(1), 195-202.

Wu, H. M., Kuo, B. C., \& Wang, S. C. (2017). Computerized Dynamic Adaptive Tests with Immediately Individualized Feedback for Primary School Mathematics Learning. Educational Technology \& Society, 20(1), 61-72.

Yang, T. C., Hwang, G. J., \& Yang, S. J. H. (2013). Development of an adaptive learning system with multiple perspectives based on students' learning styles and cognitive styles. Journal of Educational Technology \& Society, 16(4), 185-200.

Zimmer, T. (2014). Rethinking higher ed: A case for adaptive learning. Forbes, October, 22, 2014. 